\title{
THE TREATMENT OF COMPLETE HEART BLOCK
}

\author{
L. D. Abrams, M.B.(Birm.), F.R.C.S. \\ Consultant Surgeon, United Birmingham Hospitals \\ W. A. Hudson, M.B.(Shefr.), M.R.C.P. \\ Senior Medical Registrar, United Birmingham Hospitals
}

From the Queen Elizabeth Hospital, Birmingham

WHEN complete heart block gives rise to symptoms they are due to episodes of circulatory arrest or to circulatory insufficiency. Patients may suffer from either or both of these conditions.

\section{Circulatory Arrest}

Circulatory arrest produces sudden attacks of unconsciousness of two types, which may occur not only in established complete heart block, but also during sudden changes in conduction. The classical Stokes-Adams seizure is caused by ventricular arrest. The second type of attack is associated with ventricular hyper-irritability, leading to ventricular ectopic beats, often multifocal, ventricular tachycardia and ventricular fibrillation. Both types of attack may occur in one patient, and it may be difficult without detailed history-taking, clinical examination and an electrocardiogram to distinguish between them. The distinction is of more than academic importance, since it influences therapy. The most effective pharmacological agents in the management of Stokes-Adams seizures due to ventricular arrest are the sympathetico-mimetic amines, adrenaline, ephedrine and isopropyl noradrenaline (isoprenaline); these drugs increase cardiac rhythmicity and contractility and accelerate the idioventricular rate. They may be effective in preventing or diminishing the frequency of Stokes-Adams seizures. Adrenaline, ephedrine and, to a lesser degree, isoprenaline do, however, increase myocardial irritability and may therefore precipitate ventricular tachycardia and ventricular fibrillation, which are heralded by the occurrence of coupled beats (Fig. I). Sympathetico-mimetic amines are therefore contra-indicated if the attacks are due to ventricular acceleration and their use in StokesAdams seizures due to arrest is limited if ventricular arrhythmias are produced.

\section{Circulatory Insufficiency}

Circulatory insufficiency is the result of low or fixed cardiac output. The cardiac output is the $\frac{0}{3}$ product of the ventricular rate and the stroke volume. Complete heart block without arrhythmias is symptomless if the idioventricular rate is rapid or if, in the presence of a slow ventricular in rate, the cardiac output can be maintained by an $\overrightarrow{0}$ increase in stroke volume.

Starzl, Gaentner and Baker (r955) studied surgically-induced acute complete heart block in 603 dogs. An immediate reduction in cardiac output was observed in all experiments. With idio $\overrightarrow{\vec{\varphi}}$ ventricular rates of 90 or above, stroke volume increases were of such magnitude that the fall î. cardiac output was minimal. With an idiof ventricular bradycardia below 90 further increase in stroke volume did not occur and the cardiac output was diminished by the fraction idioventricular rate

90

This state persisted for a few hours, after which the cardiac output rose over a period of 10 to 18 days (due to a further slower increase in stroke volume), though only then attaining $80 \%$ of preoperative values.

Clinically, it is recognized that isolated congenital complete heart block is usually symptomless. Here the idioventricular rate is usually higher than in acquired complete heart block, and a 을 healthy myocardium can provide the larger stroke $\rightarrow$ volume to maintain an adequate cardiac output at rest and provide an increase in cardiac output on N effort. Alt, Walker and Smith (1930) found normal cardiac outputs at rest and on effort in a young $\mathrm{N}$ male of 22 and a young female of 24 , who had $\omega$ symptomless, probably congenital, complete heart block.

The low or fixed cardiac output state occurs $\mathbb{\&}$ when, in the presence of the fixed bradycardia of idioventricular rhythm the myocardium cannot 0 achieve the increase in stroke volume required to $\mathbb{D}$ maintain the normal cardiac output. At very slow 


\section{COMPLETE HEART BLOCK}

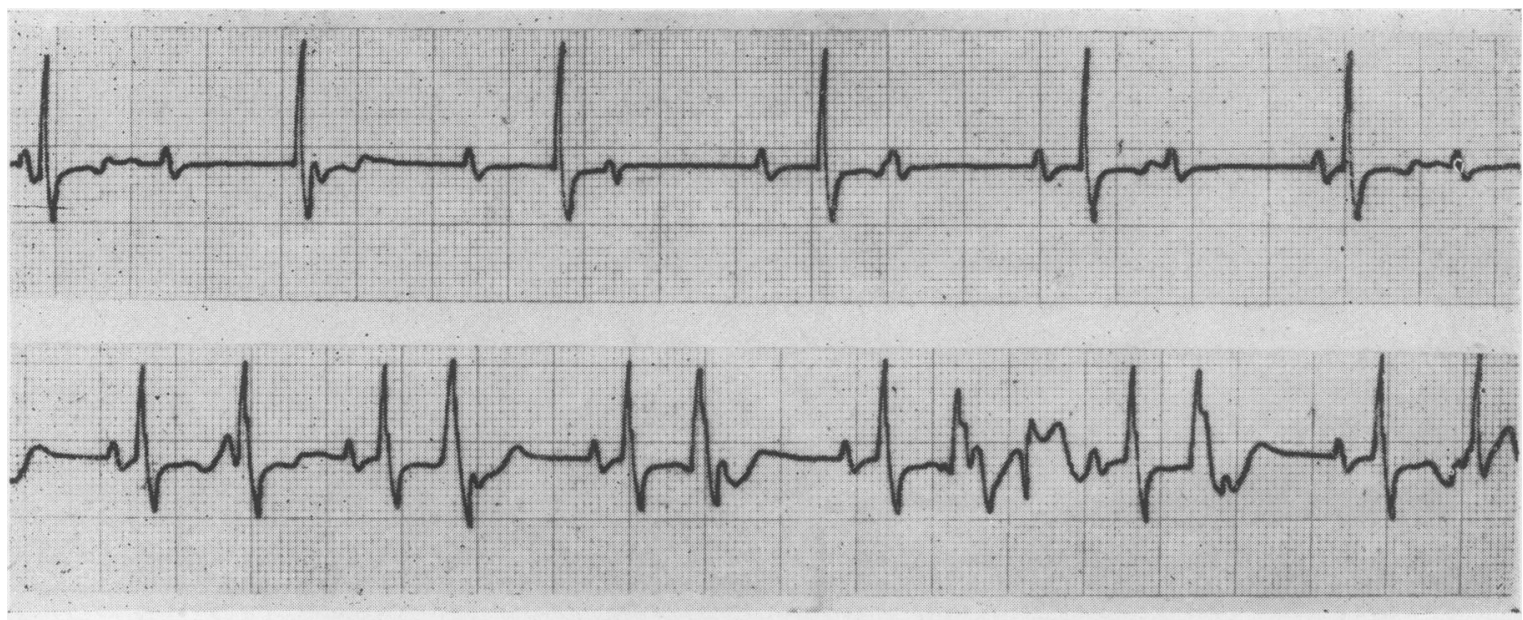

EFFECT OF ISOPRENALINE Io $\mathrm{mg}$. SUBLINGUALLY

FIG. 1.-Effect of isoprenaline, to mg., sublingually, in complete heart block. Lower record taken 30 minutes after upper record. Increase in atrial and idioventricular rates, but coupling and runs of multifocal ventricular ectopic beats have been induced.

idioventricular rates this situation might occur with an intact myocardium. At more rapid rates a low output state reflects myocardial disease. Compensation may occur by regional vasoconstriction, but patients complain of fatigue, faintness on standing or on effort, and may develop congestive cardiac failure. It is interesting that in a clinical review of $25 \mathrm{I}$ cases of complete heart block in 1956 Penton, Miller and Levine wrote:

'Congestive heart failure and dyspnœa appear to be manifestations of the underlying heart disease, and the presence of complete heart block is incidental in the course of events.

'Although we have the general impression that the slow heart rate may be actually beneficial to a certain extent, and decrease the degree of congestive cardiac failure, the observation in the study was neither detailed enough nor sufficiently adequate to offer proof in favour of this concept'.

We cannot agree. There is both experimental and clinical evidence that the idioventricular bradycardia does cause a low cardiac output and even congestive cardiac failure.

Starzl, Gaertner and Webb (1955) studied chronic surgical complete heart block in 12 dogs. All dogs showed a great reduction in exercise tolerance. The majority developed congestive cardiac failure, indolent dogs being more likely to avoid this state. At autopsy heart weights were $150 \%$ of controls, demonstrating ventricular hypertrophy due to increased work at the higher stroke volume.
Hæmodynamic studies in man have been performed by Levinson, Gunther and Meehan (I955). In five patients with complete heart block who were not in congestive cardiac failure they demonstrated increase in ventricular pressures, low cardiac outputs and increased stroke volumes. Our own catheter studies confirm these findings (Abrams, Hudson and Lightwood, 1960).

The management of complete heart block, therefore, involves treatment of Stokes-Adams seizures and the treatment of low cardiac output.

Itokes-Adams seizures threaten life. A common exitus in heart block is sudden death due to ventricular arrest or fibrillation and may occur at any time in the development of heart block or in the established state of complete heart block. When Stokes-Adams attacks become frequent and prolonged, treatment is, of course, imperative. It is an axiom that if many different forms of therapy are: advocated, then none is satisfactory. Intravenous molar lactate to promote alkalosis, ammonium chloride to promote acidosis, and steroids have all been suggested as useful agents in repeated Stokes-Adams seizures, but the most effective therapeutic agents are still the sympatheticomimetic amines. Isoprenaline (intravenously in doses of $0.2 \mathrm{mg}$., subcutaneously in the same dosage or sublingually in doses of 5 to $10 \mathrm{mg}$.) is less likely to cause ventricular acceleration than adrenaline or ephedrine (Nathanson and Miller, 1952). Our experience of medical treatment of 


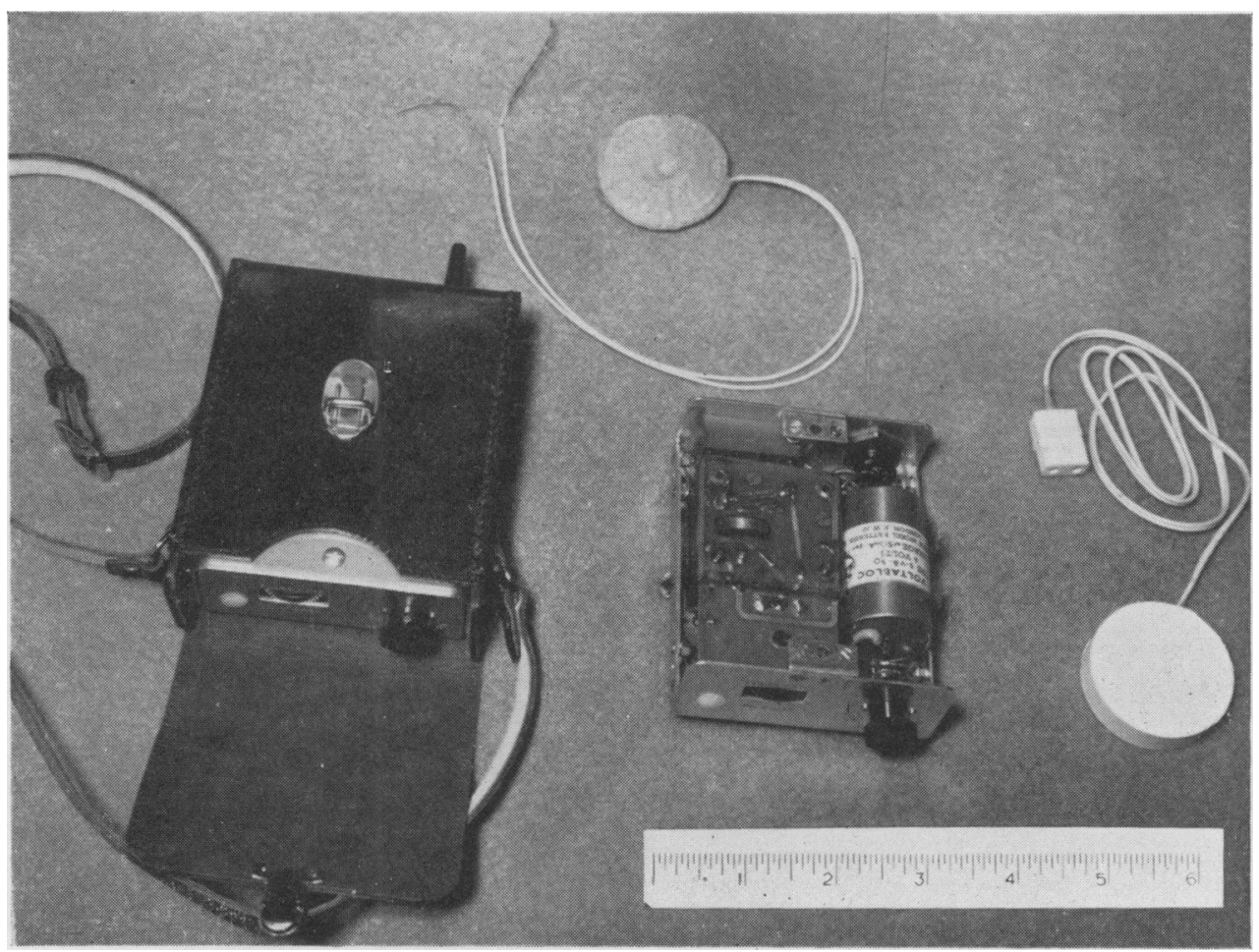

FIG. 2. - The Inductive Coupled Pacemaker. Top centre: The secondary coil (with electrodes) for implantation. Bottom right: The transistor valve generator. Bottom centre: The pulse generator removed from satchel. Bottom right: The primary coil for application to chest wall.

repeated Stokes-Adams seizures is illustrated by the following case report:

\section{Case Report}

A 77-year-old commercial engineer was still attempting to practise his profession after two years of complete heart block. He was limited by three forms of syncopal attacks. After 10 to 20 yd. of slow walking on the level he became faint due to low cardiac output. He had attacks, at rest or on effort, of sudden loss of consciousness, lasting up to one minute, associated with ventricular arrest-observed and confirmed by an electrocardiogram. These were less frequent on isoprenaline, ro mg., sublingually, four-hourly, but this regime caused an increase in a third form of attack, preceded by palpitations, which an electrocardiogram confirmed were due to runs of multifocal ventricular tachycardia. It was decided to treat him surgically, but two days before the operation was scheduled to occur he died suddenly. For this reason we treat repeated StokesAdams seizures, unsatisfactorily controlled by medical means, as acute surgical cardiac emergencies.

\section{The Surgical Treatment of Stokes-Adams Disease}

As long ago as 1932 Hyman made a plea for the use of an artificial pacemaker for the arrested heart. He quoted 65 papers concerning electrical pacemaking, reaching back as far as 1862 !
Zoll and his co-workers in $195^{2}$ (and Leatham, Cook and Davies, 1956, in this country) described successful treatment of ventricular arrest using an external pacemaker. Since then Furman and Robinson (1958) have described the use of a pacemaking cardiac catheter electrode passed into the right ventricle.

Zoll's method causes painful contractions with each stimulus, while Furman's method may lead to sepsis, venous thrombosis despite anticoagulants, and even to perforation of the heart (this has occurred on two of our cases, but without fatality). These methods are therefore temporary.

The occurrence of complete heart block after repair of ventricular septal defect provided a stimulus to a surgical approach. In the University Medical School of Minneapolis Lillehei and his associates (Weirich, Gott and Lillehei, 1957) showed that such heart block could be treated successfully with suture electrodes in the ven- 0 tricular muscle, brought out through the chest wall to a pacemaker. This is a technique that we have used in the treatment of surgical heart block and repeated Stokes-Adams seizures due to nonsurgical acquired heart block. Fracture of the 

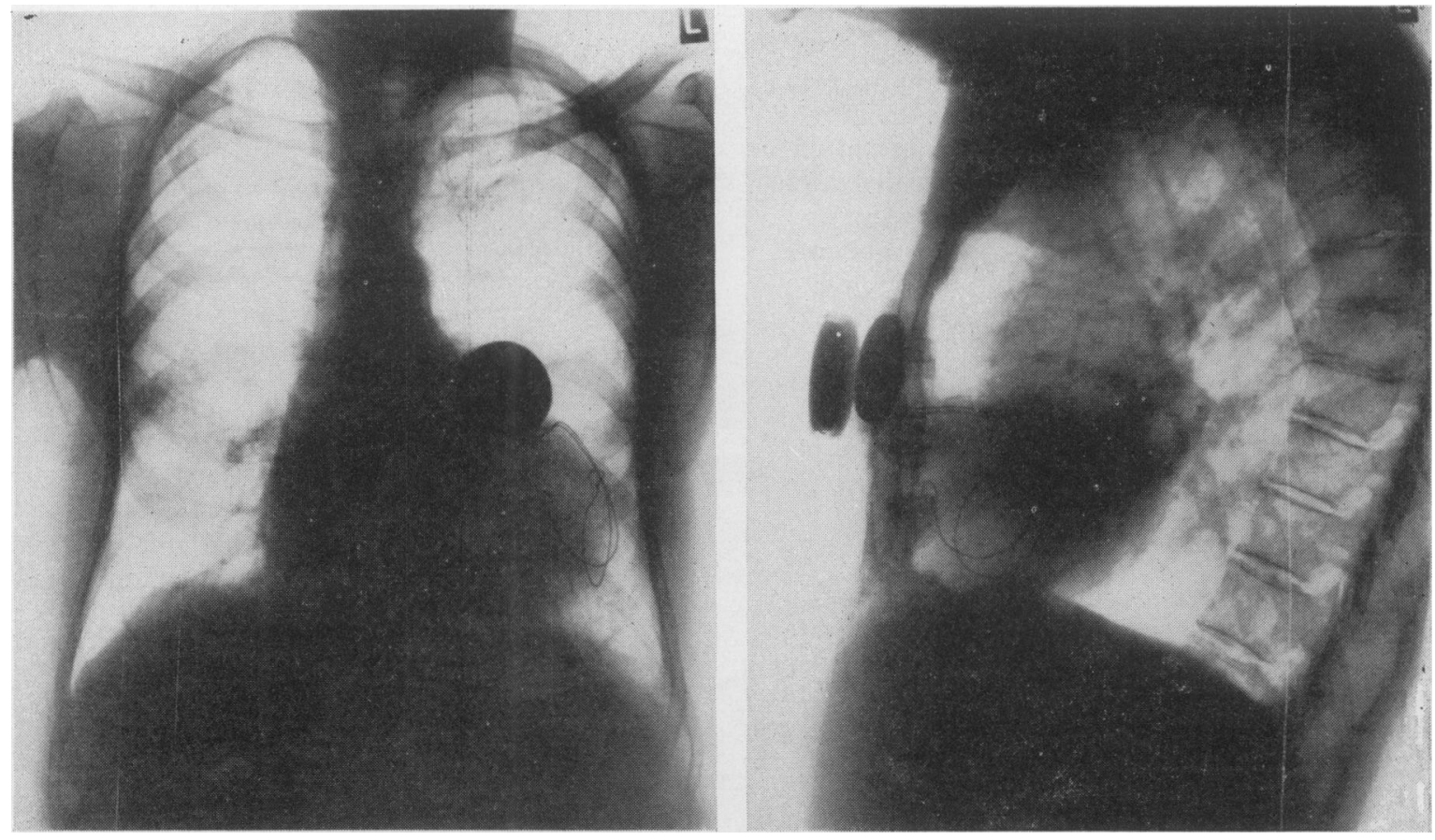

FIG. 3.-Postero-anterior chest radiograph shows the secondary coil. Left lateral chest radiograph shows the relationship of the implanted secondary coil and the external primary coil.

wires and the risk of sepsis render this method unsatisfactory for permanent use. We have therefore developed a method of painless cardiac pacemaking through the intact skin (Abrams, Hudson and Lightwood, I960). A secondary coil is placed under the skin of the chest wall and its ends in the form of braided stainless steel wires are buried in the myocardium. A pacemaking electrical impulse is induced in this by the external application of a primary coil connected to a transistor pulse generator (Figs. 2 and 3 ).

\section{The Treatment of Low Cardiac Output}

There is evidence, both experimental and clinical, that artificial pacemaking may increase the cardiac output in this state. Starzl, Gaertner and Webb (1955) demonstrated a return to normal cardiac output in induced complete heart block in dogs when they were pacemade at pre-heart block rates.

We have begun hæmodynamic studies on the pacemade human heart in patients with complete heart block. Pacemaking is achieved by the technique described by Furman and Robinson (1958), using an intra-cardiac catheter electrode.

\section{Case Report}

An engineering representative, aged 66 , who was admitted to hospital in gross congestive cardiac failure and complete heart block. He had been hypertensive for several years. On admission his mental state was dull and his manner was aggressive. His ECG showed complete AV block with an idioventricular rate of 35 . His blood pressure was $210 / 90$. There was no history of Stokes-Adams seizures.

$\mathrm{He}$ responded slowly to diuretics and was then studied. A cardiac-catheter electrode was passed from the right arm to the right ventricle. Pacemaking was achieved at 0.5 volts. A double-lumen catheter was passed from the left arm so that simultaneous pulmonary artery and pulmonary wedge pressures could be recorded. A needle was inserted in the right brachial artery.

Direct Fick cardiac outputs were measured at his idioventricular rate of 30 and at pacemaker rates of $5 \mathrm{I}$, 72 and 95. At a pacemaker rate of 72 , coincidental with a rise in cardiac output from $4.4 \mathrm{~L}$ to $5.6 \mathrm{~L} / \mathrm{min}$., and a drop in pulmonary artery and wedge pressures, the patient had striking relief of tightness in the chest and his orthopncea ceased.

Endocardial pacemaking was continued until surgery was performed four days later. During this time his congestive cardiac failure resolved and he became lucid, co-operative and pleasant in manner.

\section{Our Present Procedure}

We consider patients whose lives are in jeopardy from repeated Stokes-Adams seizures require immediate pacemaking. We also consider that pacemaking is indicated for patients disabled by low cardiac output.

Patients with repeated Stokes-Adams seizures are pacemade by the insertion, in the ward, of an 
intracardiac catheter electrode. This not only relieves the emergency, but enables the patient suffering from low cardiac output to improve, and it also allows treatment of associated conditions, such as respiratory infection. Operation can then be undertaken at a time of election, usually within two or three days.

At operation the secondary coil is implanted. Two additional wire suture electrodes are placed in the myocardium and brought out through the chest wall so that pacemaking can continue throughout the post-operative period until the wound is healed and the patient acquires confidence in the use of the primary coil. The percutaneous wire electrodes are then removed.

\section{Results}

We have achieved inductive coupled pacemaking in 12 patients. The first patient treated for repeated Stokes-Adams seizures is alive and well after one year; the patient with low output (case report No. 2) was operated on II months ago and has since led an active life.

Three patients have died following operation. One of these developed septicæmia following dilatation of a urethral stricture four months after operation. Autopsy revealed sound healing without infection around the implant. Two patients died 48 hours after operation. The first was a man of 68 with chronic bronchitis, gross emphysema and diabetes mellitus, who developed respiratory failure. The second, a man of 48 with a history of angina of effort for six months, died of left ventricular failure; autopsy revealed myocardial fibrosis.

After operation pacemaking failed in a patient aged 33 disabled by low cardiac output and jeopardized by prolonged Stokes-Adams seizures. Idioventricular rhythm returned, but was followed by circulatory arrest. The wound was reopened in the ward, cardiac massage started and ventricular fibrillation was stopped with a defibrillator. Thereafter pacemaking continued satisfactorily. The patient remains unconscious.

\section{Summary}

I. The symptoms of heart block are due to low cardiac output or circulatory arrest.

2. Medical treatment is discussed and surgical treatment in 12 patients with the inductive coupled cardiac pacemaker is described.

3. The results are briefly presented.

This work has been performed with the help of a grant from the Endowment Fund of the United Birmingham $O$ Hospitals. We wish to acknowledge the technical help we have received from our colleague, Mr. R. Lightwood, $\overrightarrow{-}$

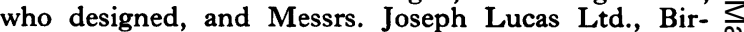
mingham, who manufacture the inductive-coupled pacemaker.

We thank Dr. A. Brian Taylor, to whose beds the majority of these patients were admitted, for his help and encouragement, and we also thank the physicians wh. have referred cases to us.

Our thanks are also due to Professor W. Melvile Arnott for facilities in his department and to Dr. N. Segel for his help with hæmodynamic studies. We thank Mr. T. F. Dee for the photographs.

\section{REFERENCES}

Abrams, L. D., Hudson, W. A., and Lightwood, R. (r960): A Surgical Approach to the Management of Heart-Block Using an Inductive Coupled Artificial Cardiac Pacemaker, Lancet, ii, 1372.

Alt, H. L., WAlkeR, G. L., and SMITH, C. W. (1930): Cardiac Output in Heart Disease: Effect of Exercise on Circulation in Patients with Chronic Rheumatic Valvular Disease, Subacute Rheumatic Fever and Complete Heart Block, Arch. intern. Med., 45, 958.

Furman, S., and Robinson, G. (1958): The Use of an Intracardiac Pacemaker in the Correction of Total Heart Block, Surg. Forum, 9, 245

Hyman, A. S. (1932): Resuscitation of Stopped Heart by Intracardial Therapy; Experimental Use of Artificial Pacemaker, Arch. intern. Med., 50, 283.

Leatham, A., Cook, P., and Davies, J. G. (1956): External Electric Stimulation for Treatment of Ventricular Stand- 을 still, Lancet, ii, 1185 .

Levinson, D. C., Gunther, L., Meehan, J. P., Griffith, G. C., and Spritzler, R. J. (r955): 'Hemodynamic Studies in Five Patients with Heart Block and Slow Ventricular Rates, Circulation, r2, 739.

Nathanson, M. H., and Miller, H. (1952): The Action of Norepinephrine, Epinephrine and Isopropyl Norepi- N nephrine on the Rhythmic Function of the Heart, Ibid., 6, 238.

Penton, G. B., Miller, H., and Levine, S. A. (I956): Some Clinical Features of Complete Heart Block, Ibid., r3, 801. N

Starzl, T. E., Gaertner, R. A., and Baker, R. R. (1955): Acute Complete Heart Block in Dogs, Ibid., $12,82$. , - , and WeBB, R. C. (1955): The Effects of Repetitive Electric Cardiac Stimulation in Dogs with Normal Hearts, Complete Heart Block and Experimental Cardiac Arrest, Ibid., Ir, 952.

Weirich, W. L., GotT, V. L., and Lillehei, C. W. (r957): The Treatment of Complete Heart Block by the Combined 6 Use of a Myocardial Electrode and an Artificial Pacemaker, Surg. Forum, 8, 360.

Zoll, P. M. (1952): Resuscitation of the Heart in Ventricular Standstill by External Electric Stimulation, New Engl. f. Med., 247, 768 .

_- Linenthall, A. J., Nozman, L. R., and Belgard, A. H. (r954): Treatment of Stokes-Adam; Disease by External Electric Stimulation of the Heart, Circulation, 9, 482. 